\title{
ALFABETIZAÇÃO CIENTÍFICA E A FORMAÇÃO DO PROFISSIONAL CIDADÃO: REFLEXÕES DO PROJETO PEDAGÓGICO DO CURSO TÉCNICO EM AGROPECUÁRIA DO IFCE CAMPUS CRATEÚS
}

\section{Scientific Literacy and the Formation of Professional Citizenship: Reflections on the Pedagogical Project of the Technical Course in Agriculture at IFCE Campus Crateús}

\author{
José Aglodualdo Holanda Cavalcante Júnior ${ }^{1}$ \\ Isabel Magda Said Pierre Carneiro ${ }^{2}$ \\ Lígia Vieira da Silva Cavalcante ${ }^{3}$
}

\begin{abstract}
Resumo: O presente trabalho apresenta uma análise, à luz dos conceitos da Alfabetização Científica (AC), do Projeto Pedagógico do Curso Técnico Subsequente em Agropecuária ofertado pelo Instituto Federal de Educação, Ciência e Tecnologia do Ceará (IFCE) campus Crateús. A perspectiva da AC tomada neste artigo é aquela cujo ensino das ciências seja empregado na construção de benefícios para as pessoas, a sociedade e o meio ambiente. Apresenta um resgate histórico da relação entre educação, trabalho e cidadania, discorrendo sobre os diversos conceitos empregados para a $\mathrm{AC}$ e o seu papel na formação de um cidadão crítico e reflexivo, bem como sobre a democratização de práticas educativas pautadas numa perspectiva de ciência-tecnologia-sociedade. A pesquisa se pautou numa abordagem qualitativa e de natureza descritiva, a partir das quais, através de uma pesquisa bibliográfica e documental, foram investigados como os conceitos de AC estão presentes no Projeto Pedagógico do Curso Técnico em Agropecuária. Os dados coletados e analisados permitem identificar elementos que aproximam o curso de um viés de AC. No entanto, verificou-se a existência de algumas lacunas, como a ausência na matriz curricular de disciplinas que tenham uma abordagem de educação cidadã. $\mathrm{O}$ estudo aponta, assim, para a necessidade de uma reformulação curricular do curso pautada nos conceitos da AC, bem como a importância da formação continuada dos docentes envolvidos no ensino técnico, propiciando aos egressos não só aptidão para o exercício de suas competências profissionais, mas tomando a educação como um processo de libertação e transformação social.
\end{abstract}

Palavras-chave: Alfabetização Científica. Educação. Cidadania. Projeto Pedagógico. Ensino Técnico.

\footnotetext{
${ }^{1}$ Doutor e mestre em Engenharia Agrícola pela Universidade Federal do Ceará (UFC). Especialista em Docência na Educação Profissional e Tecnológica (IFCE). Bacharel em Agronomia pela Universidade Federal do Ceará (UFC). Professor do Ensino Básico, Técnico e Tecnológico do Instituto Federal de Educação, Ciência e Tecnologia do Ceará (IFCE), campus Crateús. Orcid: https://orcid.org/0000-0002-2062-6890. E-mail: jose.junior@ifce.edu.br.

${ }^{2}$ Doutora e mestre em Educação pela Universidade Federal do Ceará (UFC). Bacharel em Pedagogia pela Universidade Estadual do Ceará (UECE). Pedagoga do Instituto Federal de Educação, Ciência e Tecnologia do Ceará (IFCE). Orcid: https://orcid.org/0000-0001-9214-7832. E-mail: isabelsaidifce@gmail.com.

3 Mestre em Ensino pela Universidade do Vale do Taquari (Univates). Bacharel em Serviço Social pela Universidade Estadual do Ceará (UECE). Professora e Coordenadora do Curso de Bacharelado em Serviço Social da Faculdade Princesa do Oeste. Orcid: https://orcid.org/0000-0002-7360-8477. E-mail: ligia.vieirasc86@gmail.com.
} 
Abstract: This work shows an analysis, based on the concepts of Scientific Literacy (SL), of the Pedagogical Project of the Subsequent Technical Course in Agriculture offered by the Federal Institute of Education, Science and Technology of Ceará (IFCE) campus Crateús. The SL perspective considered in this article is based on science teaching made to build benefits for people, society and the environment. This work also presents a historical overview of the relationship between education, work and citizenship, discussing the various concepts used for SL and its role in the formation of a critical and reflective citizen, as well as the democratization of educational practices concerning scientific, technological and social perspectives. The research was developed in a qualitative and descriptive approach, from which, through a bibliographic and documentary research, it was investigated how the concepts of SL are present in the Pedagogical Project of the Technical Course in Agriculture. The collected and analyzed data allow us to identify some elements which approach the course to a SL bias. However, there were some gaps, such as the absence in the curriculum matrix of disciplines with a citizen education approach. The study indicates the need for a curricular reformulation of the analyzed curriculum based on the concepts of SL, as well as the importance of continuing education for teachers involved in technical education, in order to provide graduates not only with aptitude for the practice of their professional skills, but understanding education as a process of emancipation and social transformation.

Keywords: Scientific Literacy. Education. Citizenship. Pedagogical Project. Technical Education.

\section{Introdução}

A educação, materializada especificamente nos cursos de nível técnico e superior, tem sido considerada, cada vez mais, necessária e importante no cenário atual, principalmente por ser um meio para a sobrevivência financeira e social, para o desenvolvimento humano, para preparar e qualificar os indivíduos para a realização das diversas funções no trabalho e para o exercício pleno da cidadania.

De acordo com Martins, Costa e Leite (2014), a educação é um fenômeno sociocultural que compreende os processos de ensino e de aprendizagem, que levam as pessoas à produção de conhecimento e, consequentemente, à transformação da natureza e do que está ao seu redor. Assim, a educação surge como elemento proporcionador do desenvolvimento humano, e deve estar alicerçada nos princípios da liberdade de expressão, no pluralismo de ideias e na participação democrática. Esta, segundo os autores, deve ainda visar à participação, à interdisciplinaridade e à reflexão como forma de garantir a qualidade dos seus serviços e contribuir para a formação de jovens críticos e reflexivos.

A partir desse entendimento sobre educação, consideramos importante os estudos sobre Alfabetização Científica (AC) cujo termo, neste trabalho, é empregado para designar o ensino de ciências para a formação dos estudantes, guiando o planejamento desse ensino para a construção de benefícios para as pessoas, para a sociedade e para o meio ambiente, dentro de uma perspectiva integradora das relações entre ciência-tecnologia-sociedade (CTS).

Desde meados do século XX, começaram a emergir diversas discussões sobre as relações CTS dentro de uma lógica de resposta às transformações sociais advindas com o desenvolvimento científico-tecnológico e os problemas que dele decorreram. Países da América do Norte e Europa reivindicavam uma maior participação da sociedade nos rumos do desenvolvimento científico-tecnológico. Já na América Latina havia uma contestação do modelo de desenvolvimento adotado, de cunho linear e contrário às necessidades regionais, 
gerando reivindicações por um projeto de política científica e tecnológica que fosse claro e coerente com a realidade desses países.

Tomando a realidade brasileira como foco, a educação CTS vem assumindo diferentes propósitos educacionais e abarcando discussões em torno da racionalidade científica, do desenvolvimento tecnológico e da participação social. A participação social deve ser discutida considerando diversos vieses, que vão desde a informação sobre temas socioambientais até a reivindicação pela democratização das decisões relacionadas à ciência e à tecnologia (ROSA; STRIEDER, 2018).

Tendo como ponto de partida as legislações que tratam da política de educação no Brasil, mencionamos que a Constituição Federal de 1988 (BRASIL, 1988), a Lei de Diretrizes e Bases da Educação Nacional — LDB, Lei nº 9.394/1996 (BRASIL, 1996) e, ainda, a Base Nacional Comum Curricular - BNCC ${ }^{4}$ (BRASIL, 2018), que visam o desenvolvimento da pessoa humana, sua qualificação para o trabalho e seu preparo para o exercício da cidadania, com vistas à construção de uma sociedade mais justa, democrática e inclusiva. Essas prerrogativas orientam, então, a ação das instituições de ensino na oferta de um leque de informações/conteúdos, visando à preparação do aluno-cidadão que tenha capacidade de compreender a realidade social e saiba agir sobre ela de forma crítica e compromissada.

No contexto particular dos cursos técnicos e de forma específica o Curso Técnico Subsequente em Agropecuária ofertado pelo IFCE campus Crateús, inquietamo-nos e nos propomos a pesquisar e refletir se a formação dos técnicos em agropecuária abrange as habilidades profissionais requeridas para a atuação no mercado de trabalho, mas se também segue uma perspectiva de cidadania, buscando alternativas conscientes para os problemas sociais.

$\mathrm{O}$ curso, partindo de uma perspectiva de $\mathrm{AC}$, deve estar vinculado à educação científica do cidadão e com o ensino do conteúdo da ciência no contexto autêntico do seu meio tecnológico e social. Essa educação científica deverá contribuir para que os cidadãos compreendam as utilidades da ciência, suas aplicações para melhora da qualidade de vida e também assimilem as limitações e consequências negativas que a ciência provoca. Nesse movimento, para além da formação profissional, os cursos técnicos devem ser capazes de contribuir para o melhoramento social e ambiental da região. Tais ações estão alinhadas à finalidade da educação, que é contribuir para o desenvolvimento sustentável e o melhoramento da sociedade como um todo.

Assim, este trabalho buscou investigar como os conceitos de $\mathrm{AC}$ estão presentes no Projeto Pedagógico de Curso (PPC) do Curso Técnico em Agropecuária do IFCE campus Crateús, viabilizando o repensar e o (re)significar das ações docentes e dos processos de ensino e de aprendizagem de modo a torná-los mais significativos.

Diante desse contexto, este artigo se encontra organizado da seguinte maneira: primeiramente, apresentamos algumas considerações sobre educação e trabalho na era do capital e no contexto do ensino técnico e profissional; em seguida, abordamos os conceitos de $\mathrm{AC}$ e formação cidadã; posteriormente, destacamos o percurso metodológico da pesquisa, enfocando sua abordagem, tipo e procedimento de coleta e análise de dados; na sequência, apresentamos aos resultados e discussões da investigação a partir da análise do PPC do Curso

\footnotetext{
${ }^{4}$ A BNCC, homologada em 14 de dezembro de 2018, é um documento de caráter normativo que define o conjunto orgânico e progressivo de aprendizagens essenciais que todos os alunos devem desenvolver ao longo das etapas e modalidades da educação básica.
} 
Técnico em Agropecuária, ofertado pelo IFCE campus Crateús. Por fim, seguem as considerações finais e as referências.

\section{Educação, trabalho e cidadania na era do capital}

A educação sempre esteve assimilada ao próprio processo de trabalho, seja nas sociedades primitivas, no feudalismo, no escravismo ou no modo de produção capitalista, onde as relações de trabalho promoviam/promovem processos educativos. Foi a necessidade de capacitação para o trabalho que determinou o surgimento das primeiras escolas e continuam determinando a sua modificação ao passo que o sistema se moderniza. Assim, a relação entre educação e trabalho foi se modificando com o passar do tempo. Tomamos como ponto de partida para análise a proposta feita por Saviani (2007), que é a das mudanças do modo de produção.

Antes do modo de produção capitalista (MPC), a escola era identificada, até então, como sinônimo de educação, sendo acessada, inicialmente, apenas pelas classes abastadas da sociedade, centrada em atividades intelectuais. Já a classe composta pelos escravos e serviçais não tinha o acesso à educação e o processo educativo era assimilado dentro do próprio processo de trabalho.

Com o advento do MPC, a relação entre educação e trabalho sofre uma nova determinação, pois a introdução das máquinas (indústrias) no processo produtivo passou a requerer um patamar mínimo de qualificação geral que pudesse preparar os trabalhadores para operarem essas máquinas e se adaptarem às novas circunstâncias que o MPC exigiu.

Se antes do MPC a classe trabalhadora não tinha acesso à escola porque ela era considerada como "tempo livre" e não havia essa possibilidade de ingresso, no capitalismo esse acesso será concedido e, de certa forma, obrigatório para a qualificação da mão de obra. Esse espaço de formação da mão de obra inicialmente foi ocupado pelos cursos profissionais, organizados no âmbito das empresas ou do sistema de ensino que tinham como referência o padrão escolar, mas eram determinados pelas necessidades do processo produtivo.

A palavra "escola" em grego significa o lugar do ócio. Portanto, a escola era o lugar a que tinham acesso as classes ociosas. A classe dominante, a classe dos proprietários, tinha uma educação diferenciada que era a educação escolar. Por contraposição, a educação geral, a educação da maioria, era o próprio trabalho: o povo se educava no próprio processo de trabalho. Era o aprender fazendo. Aprendia lidando com a realidade, aprendia agindo sobre a matéria, transformando-a (SAVIANI, 1994).

Ainda, de acordo com o referido autor, essa divisão da sociedade em classes coloca os homens em antagonismo, uma classe que explora e domina a outra. Atingimos, com a sociedade capitalista, o máximo de desenvolvimento da sociedade de classes. A contradição entre as classes, marca a questão educacional e o papel da escola. Assim, vinculou-se a escola ao mundo da produção, mas, nesse período, a escola não era sinônimo de educação, pois não tinha, ainda, o viés de transformação social do sujeito e da sociedade, desafio esse que perdura até aos dias atuais.

As categorias "educação", "sociedade" e "trabalho" se apresentam extremamente imbricadas quando analisadas dentro do contexto da sociedade capitalista. O modo de produção capitalista direciona os rumos de uma nação, em seus aspectos civis, sociais e políticos, por mais que esse entendimento exija uma reflexão mais acurada dos fatos. Durante o período que antecede o capitalismo, temos o trabalho e a educação desvinculados da 
construção da cidadania. O colonialismo, a aceitação do regime de escravidão, as elevadas taxas de analfabetismo e o poder público, tido como instância inacessível à população, são algumas marcas desse processo.

No Brasil, o processo de industrialização ganha contornos mais destacados a partir da década de 1930, em decorrência da nova forma de produzir, que exige homens livres e instruídos - em contraposição ao escravismo e ao analfabetismo, para operar máquinas e participar do processo de reprodução do capital. Nesse período, a cidadania brasileira começa a tomar forma com a implantação efetiva dos direitos sociais, marcando, distintivamente, o desenvolvimento da cidadania alicerçado na estrutura do Estado. É durante esse período que se expandem os cursos de formação os quais o capitalismo exige, mas ainda sem vislumbrar uma transformação social do homem na e pela educação (SAVIANI, 2007; SILVA, 2013).

Mesmo em meio ao período ditatorial, ocorre o desenvolvimento da cidadania social, reforçada pela universalização dos direitos previdenciários, extensão de diversos direitos sociais aos trabalhadores rurais e pela forte atuação do Estado na promoção do desenvolvimento econômico (SAVIANI, 2007).

O divisor de águas no processo de cidadania brasileira pode ser marcado pelo advento da Constituição Federal (BRASIL, 1988). Também conhecida como "Constituição cidadã", que apregoa a instituição de um Estado democrático, destinando, dentre outras premissas, o exercício dos direitos sociais e individuais, o bem-estar e o desenvolvimento da sociedade. Os direitos sociais estão expressos no artigo $6^{\circ}$ da Carta Magna e têm a educação como primeiro direito citado, seguido por outros como saúde, alimentação, trabalho, lazer, etc. O direito à educação é tratado especificamente nos artigos que vão do 205 ao 214 :

\begin{abstract}
Art. 205. A educação, direito de todos e dever do Estado e da família, será promovida e incentivada com a colaboração da sociedade, visando ao pleno desenvolvimento da pessoa, seu preparo para o exercício da cidadania e sua qualificação para o trabalho (BRASIL, 1988).
\end{abstract}

Merece destaque o texto da lei quando afirma que a educação visa à qualificação da pessoa para o trabalho, corroborando com o que indicamos linhas atrás, da exigência de uma mão de obra qualificada e apta para o desenvolvimento de funções requisitadas pelo capital.

Para Silva e Souza (2017), nesse contexto de democratização da educação, mas também marcado pela globalização e neoliberalismo, cresce o dilema entre a sociedade do conhecimento e a economia do conhecimento, uma vez que são colocadas novas dinâmicas e prioridades para as universidades, que ressaltam o seu papel de favorecedor da globalização da economia, mas, por vezes, pouco comprometidas com o avanço do bem-estar comum, da democracia e da justiça social.

Apesar de hoje a educação profissional ter rompido com o seu cunho assistencialista, passando a ser uma política pública de direito, ainda podemos vislumbrá-la com fortes marcas da profissionalização das classes mais vulneráveis, no sentido de formar para o mercado de trabalho, mas cujas remunerações estão aquém daquelas ocupadas pelos detentores de um diploma de nível superior.

\footnotetext{
${ }^{5}$ De acordo com Mota, Araújo e Santos (2018), a educação profissional no Brasil foi tradicionalmente relegada a segundo plano e destinada às classes menos favorecidas, apresentando um caráter muito mais assistencialista do que formativo, distanciando-se da educação propedêutica fornecida às elites.
} 
Contudo, os novos currículos contemplam disciplinas capazes de romper com esse ciclo meramente capacitador para o exercício de uma determinada função, possibilitando a reflexão sobre a vida, a sociedade, a inclusão de temas transversais (que versam sobre direitos humanos, relações étnico-raciais e educação ambiental, dentre outros temas). Estes, assim, são capazes de romper com o ciclo da alienação, promovendo a formação humana para a vida em comunidade, gerando uma transformação local e regional, impactando positivamente no futuro da nação.

A Educação Profissional e Tecnológica $(E P T)^{6}$, a partir do momento em que começa a se expandir para localidades antes silenciadas com o acesso à educação, como, por exemplo, para a região Nordeste e cidades afastadas das capitais, estas tidas como lócus privilegiado das universidades e faculdades, possibilitou romper com o ciclo elitista do acesso ao ensino.

Para Afonso e Gonzalez (2016), é inegável a contribuição da EPT dado o fomento de milhares de vagas para cursos técnicos de nível médio, cursos superiores de tecnologia e licenciaturas, o que foi um avanço se considerarmos a década anterior, quando as políticas públicas esvaziavam a responsabilidade do Estado na oferta de EPT. Contudo, esse incremento de vagas tem sido alvo de críticas de alguns setores da sociedade e de grande parte da comunidade acadêmica, pelo fato de permitir outras possibilidades de formação, não apenas a integral, a partir dos cursos técnicos integrados ${ }^{7}$, distanciando-se de uma formação mais ampla e humana e aproximando-se de uma formação mais tecnicista voltada para o mercado de trabalho.

Para Moura (2010 apud AFONSO; GONZALEZ, 2016), a oferta de cursos subsequentes ${ }^{8}$ permite preencher uma lacuna criada pelo Estado, ao não conseguir ofertar um ensino básico de qualidade, reduzindo a possibilidade dos jovens egressos do ensino médio de ingressarem no ensino superior ou de conseguirem uma colocação no mercado de trabalho que exige uma formação mais complexa.

A partir dessa colocação dos autores, compreendemos que, se, por um lado, a oferta desses cursos permite preencher uma lacuna na oferta de um ensino básico de qualidade, que possibilita tanto o ingresso no ensino superior como no mercado de trabalho, por outro, pode contribuir, também, para melhorar as condições de inserção social, política, cultural e econômica desses brasileiros. De fato, a criação e a consolidação da EPT abre um leque de possibilidades de transformação social a partir desse ensino, que se deve fazer de modo a contemplar a formação técnica e profissional e que possibilite aos educandos o ingresso no mercado de trabalho ou no ensino superior, além de visar uma formação preceituada na escola unitária gramsciana? .

\footnotetext{
${ }^{6}$ A EPT no Brasil abrange os seguintes cursos: formação inicial e continuada, educação profissional técnica de nível médio, educação profissional tecnológica de graduação e pós-graduação, conforme art. 39 da LDB (BRASIL, 1996).

${ }^{7}$ A educação profissional técnica de nível médio é desenvolvida nas formas articulada e subsequente ao ensino médio, podendo a primeira ser integrada ou concomitante a essa etapa da educação básica. A forma integrada é ofertada somente a quem já tenha concluído o ensino fundamental, com matrícula única na mesma instituição, de modo a conduzir o estudante à habilitação profissional técnica de nível médio ao mesmo tempo em que conclui a última etapa da educação básica. Já a forma concomitante é ofertada a quem ingressa no ensino médio ou já o esteja cursando, efetuando-se matrículas distintas para cada curso, aproveitando oportunidades educacionais disponíveis, seja em unidades de ensino da mesma instituição ou em distintas instituições de ensino (BRASIL, 2012).

${ }^{8}$ A educação profissional técnica de nível médio, na forma subsequente, é desenvolvida em cursos destinados, exclusivamente, a quem já tenha concluído o ensino médio (BRASIL, 2012).

${ }^{9} \mathrm{~A}$ escola unitária gramsciana visa desenvolver no indivíduo todas as suas potencialidades, tanto as de caráter muscular-nervoso quanto as de caráter intelectual. Nela, os trabalhadores devem produzir o seu próprio
} 


\section{Alfabetização científica e a formação do cidadão crítico e reflexivo}

Ao introduzirmos o termo AC, deparamo-nos com um obstáculo, que é a sua própria definição. Sasseron e Carvalho (2011) indicam que, devido à pluralidade semântica, a literatura nacional utiliza diversas expressões para designar o ensino de ciências para a formação dos estudantes, como "letramento científico", "AC" e "enculturação científica". Para as autoras, mesmo o uso de um ou outro termo indica, em linhas gerais, as mesmas preocupações com o ensino de ciências, promovendo uma positiva transformação para a sociedade.

Teixeira (2013) argumenta que a AC diz respeito a tudo aquilo que envolve a escrita e a leitura de texto científico, como a construção de entendimento e a análise das informações. Defende que a $\mathrm{AC}$ está atrelada à alfabetização na própria língua e que o ensino de ciências deve ser concebido à luz de objetivos educacionais mais amplos que o aprendizado de ciências per si (conhecimentos e procedimentos).

Sasseron e Carvalho (2011) usam o termo AC para designar as ideias que são objetivadas ao planejar um ensino que possibilite aos alunos interagir com uma nova cultura, com uma nova forma de ver o mundo e seus acontecimentos, permitindo aos alunos modificá-los e modificar a si, através da prática consciente propiciada por sua interação cercada de saberes, de noções e conhecimentos científicos, assim como das habilidades associadas ao fazer científico.

Para Chassot (2003), a AC significa dotar a população de conhecimentos científicos e tecnológicos necessários para o seu desenvolvimento na vida diária para ajudar a resolver os problemas e as necessidades de saúde e sobrevivência básica, além de propiciar a tomada de consciência das complexas relações entre ciência e sociedade.

A AC, a partir de uma perspectiva de inclusão social, deverá propiciar aos homens e às mulheres, além da compreensão da ciência, facilitar as suas inserções como sujeitos transformadores da sociedade. A AC só se realizará, de acordo com Chassot (2003), quando o ensino da ciência, em qualquer nível, contribuir para a

[...] compreensão de conhecimentos, procedimentos e valores que permitam aos estudantes tomar decisões e perceber tanto as muitas utilidades da ciência e suas aplicações na melhora da qualidade de vida, quanto às limitações e consequências negativas de seu desenvolvimento (CHASSOT, 2003, p. 99).

Ao realizarmos a AC, almejamos propiciar (a nós mesmos e aos demais sujeitos sociais) uma leitura do mundo em que vivemos, as diversas expressões da questão social que nos cercam e pensar em alternativas de transformação dessa realidade, através de pensamentos e ações críticas, éticas e conscientes.

A AC, além do desenvolvimento do pensamento autônomo, substituindo a simples transmissão do conhecimento pelo engajamento dos sujeitos em um processo que lhes permita

intelectual orgânico, capaz de compreender e refletir sobre as bases históricas, sociais e teóricas que alicerçam o mundo do trabalho, retomando a consciência dos demais indivíduos, garantindo a defesa da ideologia e do interesse de sua classe de origem. Tal educação deve ter sua centralidade no indivíduo e no seu coletivo, e não no mercado de trabalho (MOTA; ARAÚJO; SANTOS, 2018). 
interrogar o conhecimento elaborado, visa que os mesmos pensem criticamente; que enseje a resolução de problemas, estimule a discussão, desenvolva metodologias de busca e de construção de conhecimentos (ensinar com pesquisa); que confronte os conhecimentos elaborados e as pesquisas com a realidade; que mobilize visões inter e transdisciplinares sobre os fenômenos; que aponte soluções aos problemas sociais (ensinar com extensão); e que crie uma nova cultura acadêmica que valorize o trabalho dos docentes nesse contexto. Tais proposições estão alinhadas à finalidade da educação, que é de contribuir para o desenvolvimento sustentável e o melhoramento da sociedade como um todo.

Os cursos de formação, em geral, e os cursos técnicos, de forma particular, dado o recorte deste estudo, devem se pautar numa perspectiva de CTS, além de estarem vinculados à educação científica do cidadão, com o ensino do conteúdo da ciência no contexto autêntico do seu meio tecnológico e social.

Diante de tantas habilidades requisitadas para que consideremos uma pessoa como alfabetizado cientificamente, incorre-nos pensar em como o ensino de ciências - e aqui não fazemos distinção entre ciências exatas, humanas e da natureza — propiciará a aquisição dessas habilidades pelos estudantes.

Para Santos e Mortimer (2005), desde a década de 1960, currículos de ensino de ciências com ênfase em CTS vêm sendo desenvolvidos no mundo inteiro, e trazem como objetivo central a preparação dos alunos para o exercício da cidadania, caracterizando-se por realizar uma abordagem dos conteúdos científicos no seu contexto social. De acordo com Rosa e Strieder (2018), no Brasil é a partir da década de 1990 que uma proposição curricular que aponta para a abordagem das inter-relações CTS começa a ser vislumbrada, ainda que repleta de lacunas e ambiguidades.

Quando se opta por um currículo direcionado para a CTS, possibilita-se o desenvolvimento da alfabetização científica e tecnológica dos cidadãos, através de aulas que privilegiem as inter-relações entre explicação científica, planejamento tecnológico, solução de problemas, e tomada de decisão sobre temas práticos de importância social, incluindo valores éticos e princípios democráticos. Essa prática auxiliará o aluno a construir conhecimentos, habilidades e valores primordiais para a tomada de decisões responsáveis (SANTOS; MORTIMER, 2005).

Percebe-se que trabalhar o currículo numa perspectiva CTS significa incluir ativamente os alunos no contexto do ensino e da aprendizagem, abordando a ciência de forma ampla, que propicie a discussão de outros aspectos, como questões de natureza filosófica, sociológica, histórica, política, econômica e humanística (ROSENTHAL, 1989 apud SANTOS; MORTIMER, 2005).

Sasseron e Carvalho (2011) listam três eixos estruturantes da AC que devem ser considerados no momento da elaboração e planejamento de aulas que visem à AC. O primeiro se refere à compreensão básica de termos, conhecimentos e conceitos científicos fundamentais, que possibilite aos alunos aplicá-los de forma apropriada no seu dia a dia. $\mathrm{O}$ segundo eixo tem como preocupação a compreensão da natureza das ciências e dos fatores éticos e políticos que circundam sua prática. $\mathrm{O}$ terceiro e último compreende o entendimento das relações existentes entre ciência, tecnologia, sociedade e meio ambiente.

O enfoque curricular em CTS propicia a formação do sujeito para o exercício da cidadania, que, além de compreender a sociedade, reconhece o seu papel como participante nas decisões que influenciarão o futuro social, em que só uma abordagem multidisciplinar propicia. 


\subsection{Democratização das práticas educativas em CTS}

A partir das exposições traçadas sobre o movimento CTS, cabe-nos discorrer sobre a democratização ou as formas de participação dos cidadãos dentro desse enfoque. Para Rosa e Strieder (2018), existem três perspectivas distintas de democratização que têm orientado as práticas educativas CTS, cognominadas de: I) linear e hierarquizada; II) dialógica; e III) projeção conjunta e compartilhada de conhecimentos. Conhecê-las nos permitirá caminhar rumo a uma sociedade mais democrática em CTS.

A primeira dimensão é balizada por uma comunicação/interação linear e hierarquizada, de cima para baixo. O único conhecimento tido como válido é o científico, produzido por especialistas. O papel dos atores sociais é bem delimitado, pois competem aos cientistas e pesquisadores todos os direcionamentos da ciência e tecnologia (CT), sem nenhuma influência social; aos demais atores, fica a participação limitada ao recebimento de informação e formação, pois usam os produtos de origem CT, a partir de uma aceitação passiva (ROSA; STRIEDER, 2018).

As autoras fazem uma analogia dessa dimensão de democratização da CT com as práticas educacionais que se aproximam às da educação bancária proposta por Freire (2005). Nessa prática, os professores transmitem o conhecimento para os alunos, sendo eles vistos como sujeitos passivos, vazios de conhecimentos, cujo papel está na aceitação daquilo que é transmitido pelo professor especialista. Nessa dimensão, as proposições educativas são desenvolvidas apenas por especialistas - agentes externos à unidade escolar ou professores, não envolvendo outros atores - estudantes, demais docentes, comunidade escolar e comunidade local, que muito podem contribuir na definição e interação de demandas e temas a serem trabalhados. Essa prática, presente na maioria das instituições de ensino, contribui para uma limitada democratização da CT, fragilizando a construção de uma sociedade participativa frente a processos decisórios (ROSA; STRIEDER, 2018).

Corrobora, nesse sentido, os escritos de Auler (2007), ao trazer reflexões sobre os limites do modelo linear de progresso, no qual o desenvolvimento científico gera desenvolvimento tecnológico, que gera o desenvolvimento econômico, que determina então o desenvolvimento e bem-estar social. Considera-se, pois, nessa compreensão, a ideia de inevitabilidade do processo e do progresso, excluindo a sociedade da participação em decisões que envolvem seu presente e seu futuro. A suposta superioridade concedida à ciência, aliada à perspectiva de progresso inevitável e ao determinismo tecnológico, ao se transformarem em senso comum causam um efeito paralisante nos sujeitos, impedindo-os de desenvolverem suas criticidades e efetiva participação social.

A segunda dimensão de democratização da CT, tratada por Rosa e Strieder (2018), é a dialógica, que tem como base o modelo do diálogo entre atores e saberes, rompendo, ainda que parcialmente, com a lógica linear e hierarquizada. Nessa dimensão, a ciência é vista como um conhecimento essencial, porém insuficiente para identificar e solucionar todos os problemas sociais vivenciados. Os cientistas ainda são tidos como os únicos atores capazes de produzir conhecimento científico, mas se abre a possibilidade de outros conhecimentos serem considerados, uma vez que o conhecimento do especialista e sua contribuição são tidos como limitados, pois, ao se referirem a temas de outras naturezas, existe o envolvimento de outras variáveis que vão além da área científica.

Nessa dimensão, cada ator tem papel único e contribui com o que conhece e vivencia. A interação entre diferentes atores e a inclusão de outros conhecimentos, que não os técnicos 
e científicos, possibilitam a produção de saberes mais ampliados, tendo como horizonte a minimização dos problemas sociais vivenciados. Transpondo essa dimensão para a realidade escolar, temos a possibilidade de escuta das demandas e anseios dos alunos, mas ainda permanecem os professores, especialistas e gestores como os únicos capazes de produzir conhecimento.

A última dimensão, que nos possibilita refletir sobre a democratização da $\mathrm{CT}$, rompe com o pensamento e produção de CT de forma simplificada e é indicada por Rosa e Strieder (2018) como dimensão de produção conjunta e compartilhada. Nesse modelo, assim como nos dois anteriormente citados, há a essencialidade do conhecimento científico, mas se diferencia em um aspecto central: a possibilidade de produção conjunta de conhecimentos por diferentes atores sociais. Ao conhecimento científico é atribuída a possibilidade de receber influências sociais, eliminando sua suposta neutralidade. Os atores sociais, cujos papéis são de centralidade nesse modelo, têm conhecimentos e saberes que poderão ser desenvolvidos na compreensão científica, podendo ser uma contribuição para a própria ciência. Aqui a produção de conhecimento científico é voltada para atender demandas de grupos sociais, daí a necessidade de uma produção conjunta.

Em relação à educação CTS, novas maneiras de formação dos sujeitos têm surgido, engajando diferentes atores e saberes e construindo o conhecimento de maneira coletiva no processo educativo, envolvendo os alunos em todo o processo educacional. Sintetizando, Rosa e Strieder (2018, p. 19) assim resumem essa dimensão:

o destaque desta dimensão está na compreensão de uma forma de organização e pensamento complexo que podem ser contempladas, por exemplo, com propostas centradas no conceito de CTS e práticas freireanas preocupadas em envolver os estudantes em todo o processo educacional, o que inclui currículo, avaliação, gestão democrática, entre outros.

Assim, desafios se colocam à ação docente para viabilizar a democratização dos conhecimentos, incluindo alunos e também outros sujeitos (gestão, comunidade, família, etc.) nesse processo de ensino e aprendizagem mútua.

De acordo com Masetto (2010), a democracia, a participação na sociedade, o compromisso com sua evolução, a contextualização no tempo e espaço de sua civilização, a ética em suas mais abrangentes concepções (referentes tanto a valores pessoais quanto a valores profissionais, grupais e políticos) cabem no tempo e no espaço da formação de profissionais e precisam ser assumidas pela docência.

A reflexão na docência leva os professores a se posicionarem com criticidade sobre a visão de homem, de sociedade e de mundo que pretende desenvolver com seus alunos e em si mesmos. Essas atitudes serão caminhos a serem percorridos, não sem percalços, para que se atinja, de forma exitosa, uma cidadania plena, através de uma educação com qualidade, que capacite e propicie para o ingresso no mercado de trabalho, mas que também transforme a sociedade, tornando-a mais justa e igualitária.

\section{Metodologia}

Para a elaboração deste artigo, foi realizada uma pesquisa de abordagem qualitativa que, segundo Minayo (2015), responde a questões muito particulares. Esse tipo de abordagem 
trabalha com um nível de realidade social que não pode ou não deve ser quantificado. Ou seja, trabalha com o universo das relações, dos significados, dos motivos, das aspirações, das crenças, dos valores e das atitudes. Corroboram com esse entendimento de pesquisa qualitativa os escritos de Moraes e Galiazzi (2013) ao afirmarem que a mesma objetiva aprofundar a compreensão dos fenômenos que se investiga, com base em uma análise rigorosa e criteriosa.

Ainda para os autores, se, por um lado, a pesquisa qualitativa não se propõe a testar hipóteses para, ao seu fim, comprová-las ou rejeitá-las, por outro lado, tem por intenção interpretar, compreender e reconstruir conhecimentos existentes em relação ao tema investigado. Essa abordagem foi apropriada para o objetivo desta pesquisa, visto que possibilitou analisar o PPC do Curso Técnico em Agropecuária à luz da temática da $\mathrm{AC} \mathrm{e}$ tornou possível compreender as suas aproximações e distanciamentos de uma formação crítica e cidadã dos discentes vinculados a esse curso.

Para alcançarmos o objetivo proposto, realizamos uma pesquisa do tipo bibliográfica e documental. A pesquisa bibliográfica, de acordo com Gil (2008), busca conhecer as diferentes contribuições científicas sobre o fenômeno que se almeja refletir e estudar. Nessa fase da pesquisa, buscamos levantar e discorrer, a partir de pesquisas em livros, periódicos e legislações, sobre as seguintes categorias analíticas: educação e trabalho (BRASIL, 1988; 1996; 2018; MARTINS, COSTA; LEITE, 2014; SAVIANI, 1994; 2007) alfabetização científica (CHASSOT, 2003; SASSERON e CARVALHO, 2011; ROSA; STRIEDER, 2018); ensino técnico e profissional (AFONSO; GONZALEZ, 2016); profissional cidadão (ROSA; STRIEDER, 2018; SANTOS; MORTIMER, 2005).

$\mathrm{Na}$ fase da pesquisa documental, analisamos o PPC do Curso Técnico Subsequente em Agropecuária, ofertado pelo IFCE campus Crateús, em que buscamos identificar se esse contempla ou não uma abordagem de formação pautada nos conceitos de AC. Para Gil (2008), a pesquisa documental é utilizada praticamente em todas as ciências sociais e faz uso de dados já existentes provenientes de documentos, relatórios, relatos de pesquisa, etc.

A escolha pela análise documental foi feita por ela se constituir em uma importante técnica de abordagem de dados qualitativos e por possibilitar desvelar novos aspectos relacionados ao tema ou problema da pesquisa (LÜDKE; ANDRÉ, 2007). Ainda para os autores, são considerados documentos passíveis de análise: leis e regulamentos, diários pessoais, autobiografias, arquivos escolares, entre outros. Dessa forma, integrou a pesquisa documental deste trabalho o PPC do Curso Técnico em Agropecuária, que foi elaborado pelo Núcleo Docente Estruturante (NDE) do Curso, com o apoio da Coordenação Pedagógica do IFCE campus Crateús, que segue sem alterações desde o ano de 2013.

Esta pesquisa possui natureza descritiva, que, segundo Marconi e Lakatos (2018), descreve, registra, analisa e interpreta fenômenos ou situações mediante estudo realizado em determinado espaço-tempo. A pesquisa documental aconteceu entre os meses de julho e setembro de 2020. Nessa etapa, procedemos com a leitura do PPC, fazendo uma sistematização dos itens ${ }^{10}$ que apresentam termos relacionados às temáticas como: ciência, tecnologia, sociedade, cidadania, educação cidadã, responsabilidade social, transformação social, desenvolvimento sustentável, ética, criticidade/crítico e reflexão/reflexivo. Numa primeira leitura, todos esses itens foram grafados e, em seguida, uma nova leitura foi realizada, buscando identificar se os termos eram empregados dentro de uma perspectiva de $\mathrm{AC}$ e de CTS. Também identificamos os itens do projeto em que inexiste essa proposição ou

\footnotetext{
${ }^{10}$ Compõem o PPC os seguintes itens: Apresentação, Missão do IFCE, Detalhamento do c; Corpo Docente, Corpo Técnico Administrativo, Infraestrutura, Bibliografia e Anexos.
} 
que a abordagem não nos permite concluir que o curso segue uma perspectiva de AC. Os dados coletados e analisados estão sistematizados a seguir.

\section{0 curso técnico em agropecuária: análise e reflexões da proposta pedagógica}

A análise do PPC do curso técnico em Agropecuária do campus Crateús nos indica que o documento apresenta diversos elementos que o aproximam de um viés de $\mathrm{AC}$, mas que também existem algumas lacunas na construção do projeto que o distancia desse viés, como podemos perceber nos itens do referido documento analisado.

Já no item "Apresentação" aparece a descrição do IFCE como uma instituição de educação básica, profissionalizante e superior, que, para além do ensino, desenvolve atividades de pesquisa, extensão e difusão de inovações tecnológicas, com fins de atender às demandas da sociedade e do setor produtivo. Como se observa no excerto abaixo:

[...] melhorando a ação sistêmica da educação, interiorizando e socializando o conhecimento, popularizando a ciência e a tecnologia. Contribuindo dessa forma, para o desenvolvimento dos arranjos produtivos sociais e culturais locais, com foco na redução das desigualdades sociais inter e intrarregional (IFCE, 2012, p. 05).

O PPC do Curso Técnico em Agropecuária segue informando que assume o compromisso de formar profissionais competentes, com maior fundamentação teórica convergente a uma ação integradora com a prática e que esses profissionais apresentem elevados níveis de educação e qualificação, atrelados ao compromisso e à responsabilidade social para com o mundo em que vivem.

No item "Missão", o IFCE traduz uma autêntica preocupação com a AC ao afirmar que seu compromisso é de

[...] produzir, disseminar e aplicar o conhecimento tecnológico e acadêmico para formação cidadã, por meio do Ensino, da Pesquisa e da Extensão, contribuindo para o progresso socioeconômico local, regional e nacional, na perspectiva do desenvolvimento sustentável e da integração com as demandas da sociedade e com o setor produtivo (IFCE, 2012, p. 06).

Dentro da "Organização didático-pedagógica", o item "Justificativa" corrobora a preocupação com as transformações econômicas, principalmente no setor agropecuário devido à modernização no campo e a introdução de novas tecnologias, que passam a requerer profissionais com competências e habilidades que atendam tanto às demandas que emergem do mercado de trabalho como também as que promovam a sustentabilidade do sistema produtivo e alavanquem o crescimento local e regional.

Apregoa que a oferta do referido curso busca oferecer uma educação profissionalizante aos educandos, qualificando-os para atuarem nas diferentes atividades de produção animal, vegetal e agroindustrial, organização e produção dos diversos segmentos da cadeia produtiva do agronegócio, visando à qualidade e à sustentabilidade econômica, ambiental e social. Tal oferta do curso concorre, ainda, para a construção da identidade profissional dos estudantes. $\mathrm{O}$ ensino técnico profissionalizante apresenta como característica: 
[...] a formação profissional, orientando, preparando e qualificando para a sua inserção no mercado de trabalho, com as competências que garantam o aprimoramento profissional e permitam acompanhar as mudanças que caracterizam a produção no nosso tempo; o desenvolvimento das competências para continuar aprendendo, de forma autônoma e crítica, em níveis mais complexos de estudos (IFCE, 2012, p. 11).

No tocante aos "Objetivos", eles se mostram alinhados, também, à perspectiva de AC, realçando elementos como senso crítico, transformação, ética, sustentabilidade e cidadania. Vejamos alguns deles.

\begin{abstract}
Objetivo geral: proporcionar a formação técnica em Agropecuária na modalidade subsequente, articulando ensino, pesquisa e extensão a fim de desenvolver neste profissional, competências, habilidades e senso crítico para atender as necessidades de sua realidade local e regional, a fim de agir como instrumento de transformação visando aumentar a produtividade e a qualificação das produções agrícolas e zootécnicas, levando em consideração os princípios éticos, sustentáveis e de cidadania. Objetivos específicos: Capacitar os estudantes [...] com vistas a atender às necessidades de produção, bem como, de organização do agronegócio, buscando a qualidade e a sustentabilidade econômica, ambiental e social; [...] Proporcionar aos estudantes do Curso Técnico em Agropecuária conhecimentos para gerenciar projetos agrícolas nos diversos setores, inclusive econômicos, visando o desenvolvimento autossustentável com baixos custos, garantindo a melhor qualidade da vida humana, através do uso de técnicas adequadas que propiciem o desenvolvimento da agropecuária; [...] Despertar no egresso o senso crítico, a fim de que desenvolva o exercício profissional competente para analisar os processos de produção e a implantação de novas tecnologias que garantam a sustentabilidade dos sistemas agropecuários, atuando de forma empreendedora e com uma visão sustentável e de preservação ambiental (IFCE, 2012, p. 12-13).
\end{abstract}

Analisando o "Perfil profissional do egresso" encontramos a preocupação com a formação de um profissional que seja capaz de realizar as atividades requeridas pelo mercado de trabalho, mas que também seja capaz de "tomar decisões que promovam o desenvolvimento sustentável, baseado na ética e no conhecimento científico" (IFCE, 2012, p. 14).

Quanto à "Metodologia", ela está alinhada com uma educação profissional integrada às diferentes formas de educação, ao trabalho, à ciência e à tecnologia, e objetiva garantir ao cidadão o direito ao permanente desenvolvimento de aptidões para a vida produtiva e social. No PPC está explicitado que o Curso Técnico Subsequente em Agropecuária tem sua matriz curricular subdividida em disciplinas, abordando conteúdos da área agrícola, pecuária e agroindustrial, trabalhando a flexibilidade, a interdisciplinaridade e a contextualização de conteúdos indispensáveis para a formação de um profissional eclético e com uma visão ampla da produção e da comercialização, com enfoque para a preservação ambiental.

Ainda na "Metodologia", o PPC rege que os professores deverão atuar como mediadores, incentivando os alunos na construção do seu próprio conhecimento, numa relação dialógica, através do desenvolvimento de atividades que articulem teoria e prática, a partir da qual possam experimentar as diversas situações de aprendizagem de maneira contextualizada. A proposta é de uma ação pedagógica inovadora que busca superar as atividades tradicionais relativas às aulas teóricas, a partir da implementação de práticas interdisciplinares que 
alcancem todas as disciplinas do período letivo a partir da articulação entre ensino, pesquisa e extensão.

Traz, ainda, a proposta de que sejam organizados periodicamente seminários e palestras com participação direta dos alunos com realização de pesquisas, momentos para exposições e/ou sistematização e socialização do conhecimento. Esses momentos são entendidos como propiciadores para a efetivação da produção do conhecimento, por ser este fruto de discussões e de relatos de vivências que proporcionam agregar e compartilhar saberes, ressignificando, assim, o conhecimento prévio. As atividades práticas deverão ser complementadas com a realização de visitas técnicas às propriedades e empresas rurais, parques e reservas florestais, áreas de assentamentos rurais, localidades na zona rural do município, como também em municípios vizinhos e outras regiões do estado, proporcionando aos discentes contato direto com a realidade do setor produtivo da agropecuária.

É citado, por fim, que existe esse desafio, que é de qualificar tecnicamente o trabalhador através de uma metodologia que unifique cultura e trabalho, que não se restrinja ao caráter produtivo, mas que abranja dimensões comportamentais, humanísticas e intelectuais capazes de promover ações que permitam ao cidadão participar ativamente do processo de construção social.

Esses foram os elementos identificados no PPC do curso, em uma dimensão prescritiva, que convergem para a sua identificação enquanto um curso preocupado com a disseminação da ciência e da tecnologia integrada com o desenvolvimento sustentável e com vistas à transformação social de forma crítica e consciente.

Contudo, analisando a organização curricular proposta para esse curso, identificamos a ausência, na matriz curricular, de disciplinas que tenham essa abordagem de educação cidadã, que visem uma formação integral desses estudantes, preparando-os para atuar com criticidade, reflexibilidade, integrando a ciência, a tecnologia e a sociedade. Apenas as disciplinas "Extensão rural" e "Estratégias de convivência com o Semiárido" apresentam uma aproximação com essa proposta.

Ademais, os objetivos, metodologia e avaliação, constantes nos Programas de Unidade Didática (PUDs) se apresentam deslocados da proposta de uma formação integral e crítica do aluno. Os objetivos apresentam ênfase no ensino (apresentar, abordar, demonstrar, etc.), quando deveriam especificar o que se espera que o aluno desenvolva e aprenda. Aqui deveriam ser os discentes os sujeitos dos verbos, indicando os objetivos de aprendizagem. As metodologias das aulas explicitadas nos PUDs indicam, na sua maioria, que serão de forma expositiva, trazendo para o centro do processo o professor, caminhando na contramão dessa interação professor-aluno. As avaliações, por mais que apresentem uma diversidade de formatos (avaliações escritas, seminários, trabalhos extra-sala de aula, dinâmicas em sala, etc.), não nos permitem indicar que caminham para a valorização das aprendizagens, das potencialidades e do caráter reflexivo e crítico dos estudantes, como estão previstos na "Justificativa" e nos "Objetivos do curso".

Entendemos, assim, que o referido PPC busca, conforme demonstrado em alguns itens do projeto, orientar, preparar e qualificar o aluno para a sua inserção no mercado de trabalho, com as competências que garantam o aprimoramento profissional, garantindo a formação integral do cidadão e futuro profissional de agropecuária. Além disso, permitindo que os alunos acompanhem as mudanças que caracterizam a produção no nosso tempo, com competências, habilidades e senso crítico para atender as necessidades de sua realidade local e regional, a fim de agir como instrumento de transformação, visando aumentar a produtividade e a qualificação das produções agrícolas e zootécnicas, levando em consideração os princípios 
éticos, sustentáveis e de cidadania, bem como o desenvolvimento das competências para continuar aprendendo, de forma autônoma e crítica, em níveis mais complexos de estudos. Contudo, analisando a proposta dos PUDs, parece que os mesmos não caminham na direção da materialização dessa formação, dentro de uma proposta de $\mathrm{AC}$, carecendo de ajustes de maior profundidade.

Consideramos que a superação desses desafios perpassa pela ação docente, tanto na elaboração do PPC como na formação desses sujeitos que almejamos que sejam alfabetizados cientificamente. Isso decorre da própria ausência dessas habilidades no percurso formativo dos professores. Sabemos que muitos docentes que atuam nos cursos técnicos vêm de uma formação em nível de bacharelado, a qual, muitas vezes, é distanciada de reflexões voltadas para o ensino. Ao passarem por processos educativos (da educação básica ao ensino superior), foram apenas receptores de conhecimentos, já trazidos como prontos, acabados e inquestionáveis, não estimulando nenhum processo de curiosidade, questionamento e aplicação na realidade (ALMEIDA, 2012; MASETTO, 2012; SANTOS; POWACZUK, 2012).

Essa educação bancária, da qual foram, um dia, os sujeitos passivos, acaba sendo reproduzida por diversos docentes com os seus atuais alunos. O professor continua tendo centralidade no processo de ensino, e suas aulas, muitas vezes, baseiam-se em cópias, memorizações e exercícios com conteúdos que apresentam pouca ou nenhuma significância para o aluno, com currículo e disciplinas "engessadas" que não dialogam entre si, criando barreiras para a aprendizagem numa perspectiva de cidadania plena.

Essa formação crítica e cidadã, por mais que seja mencionada nos projetos pedagógicos, nem sempre é materializada, por isso, advogamos para que tal inclusão e materialização ocorram efetivamente. Os professores, se ainda não têm preparação para atuar nessa perspectiva, podem agregar essas habilidades ao seu processo formativo e transmiti-las aos alunos. Cabe às instituições de ensino e às instâncias que legislam e financiam a educação maior investimento nesse sentido. Só conseguiremos atingir a excelência de sujeitos alfabetizados cientificamente quando tais propostas forem concretizadas.

\section{Considerações finais}

A proposição deste trabalho foi analisar como os conceitos de AC estavam presentes no PPC do Curso Técnico em Agropecuária do IFCE campus Crateús, e como esse projeto poderia ser reformulado com o objetivo de tornar o curso propulsor de uma verdadeira $\mathrm{AC}$, possibilitando (re)significar as ações docentes e os processos de ensino e de aprendizagem.

Assim, a partir do objetivo traçado, acreditamos ser urgente e necessária a reformulação do PPC para que possa prever a inclusão de temas transversais, como ética, direitos humanos, relações étnico-raciais, meio ambiente, dentre outros, pois são questões importantes e imperativas, presentes no cotidiano, que se trabalhadas didaticamente promoverão uma educação cidadã e transformadora.

Sugerimos a reformulação dos PUDs, destinando atenção especial na construção dos objetivos, metodologia e avaliação, trazendo o aluno para o centro do processo de ensino e aprendizagem. Entendemos ser, também, necessário explicitar como se dará a realização das relações interdisciplinares e transdisciplinares propostas na metodologia do referido PPC.

No que diz respeito ao currículo do Curso Técnico em Agropecuária, é oportuno que propicie ao egresso aptidão para exercer suas competências profissionais na forma atualmente 
exigida pelas unidades empregadoras, mas que também esse mesmo currículo seja capaz de suscitar importantes reflexões no tocante ao papel da educação para além da capacitação para o exercício de atividades laborativas, tomando, assim, a educação como processo libertador, capaz de impactar positivamente o futuro de uma nação, através da transformação social. Disciplinas como "Extensão rural", "Técnicas de convivência com o Semiárido" e "Princípios agroecológicos" são algumas das quais é possível refletir sobre a função da educação e do trabalho como transformação social.

A partir do momento que o currículo do curso contemplar disciplinas e conteúdos que possam ir além da mera capacitação para o exercício de atividades laborativas, já temos um primeiro passo nesse trilhar da AC. O segundo passo é que os docentes, cientes do seu importante papel nesse processo - tanto na elaboração do PPC como na mediação dos processos de ensino e aprendizagem -, junto aos seus pares e com os discentes, possam tomar a educação como um processo libertador, processo de conhecimento da própria sociedade, que capacite os homens para transformar essa realidade.

A partir das análises e reflexões propiciadas por este estudo, inferimos a necessidade de uma reformulação no PPC do Curso Técnico em Agropecuária do IFCE campus Crateús, bem como a formação continuada dos docentes no que tange ao conteúdo proposto neste artigo.

Almejamos, ainda, que este estudo possa servir de âncora para o desenvolvimento de outras pesquisas semelhantes a esta, sejam no âmbito do IFCE ou em outras instituições de ensino, em que se busque a preocupação com a formação do profissional e cidadão.

\section{Referências}

AFONSO, A. M. M.; GONZALEZ, W. R. C. Educação Profissional e Tecnológica: análises e perspectivas da LDB/1996 à CONAE 2014. Ensaio: Avaliação e Políticas Públicas em

Educação, v. 24, n. 92, p. 719-742, 2016.

ALMEIDA, M. I. Formação do professor do ensino superior: desafios e políticas institucionais. São Paulo: Cortez, 2012.

AULER, D. Enfoque Ciência-Tecnologia-Sociedade: pressupostos para o contexto brasileiro. Ciência \& Ensino. v. 1, número especial, 2007.

BRASIL. Constituição da República Federativa do Brasil: promulgada em 5 de outubro de 1988. Disponível em: http://www.planalto.gov.br/ccivil_03/constituicao/constituicao.htm.

Acesso em: 18 set. 2019.

BRASIL. Lei $n^{\circ}$ 9.394. Estabelece as diretrizes e bases Ciência e Educação da educação nacional, de 20 de dezembro de 1996. Presidência da República. Brasília, DF. Disponível em: http://www.planalto.gov.br/CCIVIL_03/Leis/L9394.htm. Acesso em: 20 out. 2019.

BRASIL. Resolução n ${ }^{\circ}$ 6, de 20 de setembro de 2012. Define Diretrizes Curriculares

Nacionais Para A Educação Profissional Técnica De Nível Médio. Brasília: Ministério da Educação, 2012. Disponível em: 
http://portal.mec.gov.br/index.php?option=com_docman\&view=download\&alias=11663-rceb 006-12-pdf\&category_slug=setembro-2012-pdf\&Itemid=30192. Acesso em: 03 out. 2020.

BRASIL. Base Nacional Comum Curricular (BNCC). Brasília: MEC/Secretaria de Educação Básica, 2018. Disponível em:

http://basenacionalcomum.mec.gov.br/images/BNCC_EI_EF_110518_versaofinal_site.pdf. Acesso em: 20 out. 2019.

CHASSOT, A. Alfabetização científica: uma possibilidade para a inclusão social. Revista Brasileira de Educação, n. 22, p. 89-100, 2003.

FREIRE, P. Pedagogia do oprimido. 48. ed. Rio de Janeiro: Paz e Terra, 2005.

GIL, A.C. Métodos e técnicas de pesquisa social. 6. ed. São Paulo: Atlas, 2008.

INSTITUTO FEDERAL DE EDUCAÇÃO, CIÊNCIA E TECNOLOGIA (IFCE). Projeto pedagógico do curso técnico em agropecuária. IFCE: Crateús, 2012.

LÜDKE, M.; ANDRÉ, M. E.D. Pesquisa em educação: abordagens qualitativas. 10 ed. São Paulo: EPU, 2007.

MARCONI, M. A.; LAKATOS, E. M. Técnicas de pesquisa. 8. ed. São Paulo: Atlas, 2018.

MARTINS, E. S.; COSTA, E. A. S.; LEITE, M. C. S. R. Gestão e cotidiano escolar: espaço de reflexão? Revista Educação e Linguagens, v. 3, n. 5, 2014.

MASETTO, M. T. Competência pedagógica do professor universitário. 2. ed. São Paulo: Summus, 2012.

MASETTO, M. T. Docência no ensino superior voltada para a aprendizagem faz a diferença. Cadernos Pedagogia Universitária. USP. 2010. Pró-Reitoria de Graduação da USP.

Disponível em: http://www.prpg.usp.br/attachments/article/640/Caderno_12_PAE.pdf. Acesso em: 27 set. 2019.

MINAYO, M. C. S. O desafio da pesquisa social. IN: MINAYO, M. C. S (Org.). Pesquisa social: teoria, método e criatividade. 34. ed. Petrópolis: Vozes, 2015.

MORAES, R.; GALIAZZI, M. C. Análise Textual Discursiva. 2. ed. Ijuí: Unijuí, 2013.

MOTA, K. R.; ARAÚJO, C. H.; SANTOS, B.G. a formação para o trabalho: o papel dos institutos federais na produção dos novos intelectuais. HOLOS, v. 2, p. 351-364, 2018.

ROSA, S. E.; STRIEDER, R. B. Dimensões da democratização da ciência-tecnologia no âmbito da educação CTS. Revista Insignare Scientia-RIS, v. 1, n. 2, 2018.

SANTOS, W. L. P., MORTIMER, E. F. Uma análise de pressupostos teóricos da abordagem C-T-S (Ciência - Tecnologia - Sociedade) no contexto da educação brasileira. Pesquisa em Educação em Ciências, v.2, n.2, 2005. 
SANTOS, E. A. G; POWACZUK, A. C. H. Formação e Desenvolvimento Profissional Docente: a aprendizagem da docência universitária. Políticas Educativas, v. 5, n. 2, 2012.

SASSERON, L. H.; CARVALHO, A. N. P. Alfabetização científica: uma revisão bibliográfica. Investigações em ensino de ciências, v. 16, n. 1, p. 59-77, 2011.

SAVIANI, D. O trabalho como princípio educativo frente às novas tecnologias. Novas tecnologias, trabalho e educação: um debate multidisciplinar. Petrópolis: Vozes, p. 147-164, 1994.

SAVIANI, D. Trabalho e educação: fundamentos ontológicos e históricos. Revista brasileira de educação, v. 12, n. 34, p. 152-165, 2007.

SILVA, S. A. da. Políticas e programas da EPCT. Fortaleza: SETEC/IFCE, 2013.

SILVA, S. H. S. C.; SOUZA, F. C. S. Bacharéis que se tornam professores: inserção e prática profissionais de engenheiros no ensino superior. HOLOS, v. 5, p. 197-213, 2017.

TEIXEIRA, F. M. Alfabetização científica: questões para reflexão. Ciência \& Educação, v. 19, n. 4, p. 795-809, 2013.

Recebido em março de 2021.

Aprovado em maio de 2021. 